\title{
Dual-labeled chemiluminescence enzyme immunoassay for simultaneous measurement of total prostate specific antigen (TPSA) and free prostate specific antigen (FPSA)
}

\author{
Lixia Zhao ${ }^{1}$ (i) | Dan Wang ${ }^{1,3}$ | Gen Shi ${ }^{1}$ | Ling Lin $^{2}$
}

\author{
${ }^{1}$ State Key Laboratory of Environmental \\ Chemistry and Ecotoxicology, Research Center \\ for Eco-Environmental Sciences, Chinese \\ Academy of Sciences, Beijing, China \\ ${ }^{2}$ The National Center for Nanoscience and \\ Technology (NCNST) of China, Beijing, \\ People's Republic of China \\ ${ }^{3}$ University of Chinese Academy of Sciences, \\ Beijing, People's Republic of China \\ Correspondence \\ Lixia Zhao, Research Center for Eco- \\ Environmental Sciences, Chinese Academy of \\ Sciences, Beijing, 100085, China. \\ Email: zlx@rcees.ac.cn \\ Ling Lin, Then National Center for \\ Nanoscience and Technology (NCNST) of \\ China, No. 11 ZhongGuanCun, 100190 \\ Beijing, People's Republic of China. \\ Email: linling@nanoctr.cn \\ Funding information \\ National Key Research and Development \\ Program of China, Grant/Award Number: \\ 2016YFA0203102; Chinese Academy of \\ Sciences, Grant/Award Number: \\ XDB14040100; National Natural Science \\ Foundation of China, Grant/Award Number: \\ 21677152 and 21177138
}

\begin{abstract}
The specificity for early diagnostic of prostate-specific antigen (PSA) is low because the current technology mostly allows the detection of only one biomarker at one time. In this work, a duallabeled chemiluminescence enzyme immunoassay (CLEIA) for simultaneous measurement of total PSA (TPSA) and free PSA (FPSA) was proposed. Anti-PSA McAb (Mab1) was immobilized on a microplate as the solid phase, horseradish peroxidase (HRP)-labeled anti-TPSA monoclonal antibody (McAb2) and alkaline phosphatase (ALP)-labeled anti-FPSA McAb3 were used as detection antibodies. Two chemiluminescence reactions of HRP with luminol and ALP with 4-methoxy-4-(3-phosphate-phenyl)-spiro-(1,2-dioxetane-3,2'-adamantane) (AMPPD) were used as the signal detecting system. Based on a sandwich model, the amount of FPSA and TPSA could be determined simultaneously. The effects of several physico-chemical parameters were studied and optimized. Cross-reactivities of six common tumor markers in serum were studied. The proposed method presented the sensitivity of $0.03 \mathrm{ng} \mathrm{ml}^{-1}$ and $0.05 \mathrm{ng} \mathrm{ml}^{-1}$ for FPSA and TPSA respectively, with low cross-reactivities. Compared with the results from commercial chemiluminescent kits there was good correlation, indicating that this established method could be used to simultaneously to measure the concentrations of FPSA and TPSA in one serum sample and also could greatly facilitate the early diagnosis for PCa in clinical practice.
\end{abstract}

\section{KEYWORDS}

chemiluminescent enzyme immunoassay (CLEIA), dual-labeled, free prostate specific antigen (FPSA), simultaneous measurement, total prostate specific antigen (TPSA)

\section{1 | INTRODUCTION}

Prostate cancer ( $\mathrm{PCa}$ ) is one of the leading causes of male death from tumors. Prostate-specific antigen (PSA) is a single chain glycoprotein with molecular weight $28.4 \mathrm{kDa}$, and is secreted by the epithelial cells of the prostate gland. Levels of PSA are increased in the serum of patients with prostate cancer. Therefore, PSA is a

Abbreviations used: ALP, alkaline phosphatase; $\mathrm{BPH}$, benign prostate hyperplasia; BSA, bovine serum albumin; CEA, carcino-embryonic antigen; CR, cross-reactivity; CV, coefficient of variation; DPC, Diagnostic Products Corporation; ELISA, enzyme-linked immunoadsorbent assay; FPSA, free prostate specific antigen; LOD, Llimit of detection; NCNST, National Center for Nanoscience and Technology; PBS, phosphate-buffered saline; PLA, People's Liberation Army; PSA, prostate-specific antigen; RLU, relative luminescence unit; RT, room temperature; TPSA, total prostate specific antigen. reliable tumor marker for $\mathrm{PCa}$ and has been used to monitor the patient's response to treatment for approximately 20 years. ${ }^{[1]}$ PSA levels, however, increase in serum in patients with benign prostate hyperplasia (BPH), as well as in males of increased age. The range 2-20 $\mathrm{ng} \mathrm{ml}^{-1}$ for PSA levels is named the 'diagnostic gray zone' in the clinical screening for PCa. ${ }^{[2-4]}$ PSA has at least four different molecular forms in human serum, of which free PSA (FPSA) and PSA bound to a1-antichymotrypsin (PSA - ACT) were the two major forms. ${ }^{[2,5]}$ The difference of FPSA concentration in human serum could improve the discrimination between $\mathrm{BPH}$ and PCa, because the proportion of FPSA to total prostate specific antigen (TPSA) (F/ T PSA ratio) in PCa patient serum was lower than that in the $\mathrm{BPH}$ patient or a healthy person. ${ }^{[6,7]}$ Therefore, the simultaneous measurement for FPSA and TPSA concentrations and the calculation 
for the F/T PSA ratio could greatly contribute to meet the requirement in clinical diagnostic specificity for PCa in those whose PSA level was in the 'diagnostic gray zone'.

There were some approaches that used nucleic acids for PSA detection, most of these applied immunoassays to detect TPSA or FPSA concentrations in the serum samples based on different detection protocols. Radioimmunoassay $(R I A),{ }^{[8]}$ enzyme-linked immunoadsorbent assay (ELISA), ${ }^{[4]}$ and fluorescence immunoassay (FIA) ${ }^{[9,10]}$ have been used previously. These methods have some issues, such as waste disposal for radiolabels, expensive lanthanide labels for fluoroimmunoassay, and low sensitivities of ELISA. Other immunoreaction-based methods, such as surface plasmon resonance $(\mathrm{SPR})^{[11]}$ or surface-enhanced Raman scattering (SERS), [12,13] required complicated and expensive instruments that made them difficult in practical diagnosis screening. Chemiluminescent immunoassay (CLIA) including chemiluminescence enzyme immunoassay $(\text { CLEIA })^{[14,15]}$ and electrochemiluminescence ${ }^{[16,17]}$ have been developed and adopted in routine clinical analysis for the high sensitivity determination of TPSA or FPSA. However, almost all of the aforementioned methods are either only for the detection of TPSA or only for the measurement of FPSA, which usually results in unmatched $F / T$ ratios. ${ }^{[18-20]}$ Furthermore, two separated measurements would unavoidably result in bigger errors than the simultaneous assay because of different effects of pipetting error in each analyte that could be eliminated using the simultaneous assay. Therefore, an immunological method design for the simultaneous assay of FPSA and TPSA is necessary. To the best of our knowledge, only Zhu ${ }^{[2]}$ and Wang ${ }^{[21]}$ have reported two different fluoroimmunoassay methods for simultaneous detection of total PSA (TPSA) and free PSA in human serum. However, the sensitivity was limited due to the fluorescence detection. In addition, lanthanide labels for time-resolved fluorescence immunoassay (TRFIA) are expensive and susceptible to outside interference.

Enhanced chemiluminescence has been widely applied for a variety of detection assays in biology due to its high sensitivity, linear range and easy automation, usually using an enzyme as label to link with an antibody or antigen that specifically recognizes the molecule of interest. ${ }^{[22-25]}$ In the present study, a dual-labeled chemiluminescent enzyme immunoassay (CLEIA) for the simultaneous measurement of TPSA and FPSA was designed, using dual labeling of antiTPSA monoclonal antibody (McAb) with horseradish peroxidase (HRP) and anti-FPSA McAb with alkaline phosphatase (ALP). For capture, anti-PSA McAb (Mab1) was immobilized on a microplate acting as the solid phase, two sandwiched immunocomplexes were formed in the reaction between anti-PSA McAb (Mab1)-TPSA antigen - HRP-labeled anti-TPSA McAb (Mab 2) and anti-PSA McAb (Mab1) - FPSA antigen - ALP-labeled anti-FPSA McAb (Mab 3). The subsequent chemiluminescence reactions of HRP with luminol and ALP with 4-methoxy-4-(3-phosphate-phenyl)-spiro-(1,2-dioxetane3,2 '-adamantane) (AMPPD) gave light intensity that was respectively proportional to the amount of TPSA and FPSA in the samples. The method has been demonstrated to allow fast and reliable detection of TPSA and FPSA simultaneously in one serum sample. It is also less expensive than available commercial assays and easily applied for the routine testing.

\section{2 | EXPERIMENTAL}

\section{1 | Apparatus}

A BHP 9504 microplate reader was employed for chemiluminescence intensity detection that was obtained from Hamamatsu (Hamamatsu Co., Ltd, Beijing, China). A microplate mixer from Beijing Xinjingke Biotechnology Co. Ltd, Beijing, China, was used to blend the solutions in microwells. A DEM-3 microtiter plate washer (Beijing Tuopu Analytical Instrument Co., Ltd, Beijing, China) was used for plate washing. An electric heat constant temperature incubator from the Beijing Chang'an Science Instrument Company was used to heat the microplate. The 96-well microplates were from Shenzhen Jincanhua Co., Ltd, China.

\section{2 | Chemicals and immunoreagents}

PSA was purified from human seminal plasma at the General Hospital of Chinese PLA (People's Liberation Army). Anti-PSA McAbs were purchased from Fitzgerald. Co. Ltd, USA. HRP, ALP and polyoxyethylenesorbitan monolaurate (Tween 20) were purchased from Sigma-Aldrich Co. Ltd, USA. The chemiluminescent substrate AMPPD for ALP and luminol for HRP were obtained from Diagnostic Products Corporation (DPC) Co. Ltd and Sigma-Aldrich. Bovine serum albumin (BSA) was from Merck Co. Ltd, Germany. Commercial chemiluminescence kits for TPSA or FPSA were from Monobind Co. Ltd, USA. HRP-labeled anti-PSA McAb was provided by the Chem Clin. Co. Ltd, China.

\section{3 | Buffers, calibrators and samples}

Highly purified distilled and deionized water was used throughout the study. The coating buffer consisted of $0.05 \mathrm{~mol} \mathrm{~L}^{-1}$ carbonate buffer (pH 9.5). The blocking buffer was made with $0.1 \mathrm{~mol} \mathrm{~L}^{-1}$ phosphatebuffered saline (PBS) and $1 \%(w / v)$ BSA solution as well as $5 \%(w / v)$ sucrose. The washing buffer was $0.1 \mathrm{~mol} \mathrm{~L}^{-1}$ PBS with $0.1 \%(\mathrm{v} / \mathrm{v})$ Tween-20. The PSA calibrators were prepared in 50\% calf serum and sodium chloride solution $(0.9 \%, w / w)$ (with a volume ratio of $1: 1$, $\mathrm{pH} 7.0-7.2$ ) and $0.5 \%$ proclin-300 with concentrations of 0, 2.0, 5.0, 10,25 , or $50 \mathrm{ng} \mathrm{ml}^{-1}$, designated as $\mathrm{S}_{0}, \mathrm{~S}_{1}, \mathrm{~S}_{2}, \mathrm{~S}_{3}, \mathrm{~S}_{4}$, and $\mathrm{S}_{5}$, respectively, and then stored at $4^{\circ} \mathrm{C}$ until further use. The serum samples provided by the General Hospital of Chinese PLA were analyzed without any pretreatment.

\section{4 | Immunoassay}

The immunoassay features are presented in Figure 1. PSA exists in serum as FPSA and PSA - ACT as the two main forms, so usually TPSA is refered to as the sum of FPSA and PSA - ACT. The capture antibody (Mab1) was coated onto the surface of solid phase, which recognized both FPSA and PSA - ACT. The HRP-labeled antibody (Mab2) also recognized both FPSA and PSA - ACT. Both of these could be used to measure TPSA in the sample. Whereas, ALP-labeled antibody (Mab3) only recognizes FPSA, so it could be used to measure FPSA in the sample. 
FIGURE 1 Immunoassay features of the proposed dual-labeled immunoassay for measuring FPSA and TPSA

\section{5 | Immunoassay procedures}

\subsection{1 | Preparation of ALP-labeled anti-FPSA McAb}

The glutaraldehyde cross-linking method was used to label ALP on antiFPSA IgG antibody, the details are as follows: $4 \mathrm{mg}$ of anti-FPSA IgG antibody and $5 \mathrm{mg}$ of ALP were added to $0.5 \mathrm{ml}$ of sodium chloride solution $(0.9 \%, w / w)$ and dialyzed for $24 \mathrm{~h}$ at $4^{\circ} \mathrm{C}$ against $0.01 \mathrm{M}$ PBS buffer at $\mathrm{pH}$ 7.2. Then $0.1 \mathrm{ml}$ of ethanolamine $\left(1.0 \mathrm{~mol} \mathrm{~L}^{-1}\right)$ was added to the above solutions and incubated for another $2 \mathrm{~h}$ at room temperature (RT) $\left(18-25^{\circ} \mathrm{C}\right)$. Then, the mixture was dialyzed for $12 \mathrm{~h}$ against 0.01 M PBS buffer at $\mathrm{pH} 7.2$ to remove free ALP or IgG molecules. The fractions containing ALP-labeled IgG were pooled and an equal volume of glycerol was added, mixed, and stored at $-20^{\circ} \mathrm{C}$ for further use.

\subsubsection{Solid phase antibody preparation}

The wells of the microtiter plates were coated with $100 \mu$ l of anti-PSA antibody $\left(5 \mu \mathrm{g} \mathrm{ml}^{-1}\right)$ in carbonate buffer $\left(0.05 \mathrm{~mol} \mathrm{~L}^{-1}, \mathrm{pH}\right.$ 9.6). The plates were allowed to stand sealed at $4^{\circ} \mathrm{C}$ for $15 \mathrm{~h}$. Then, plates were washed three times washing and post-coated with $300 \mu$ l of blocking buffer for $2 \mathrm{~h}$ at $37^{\circ} \mathrm{C}$. After that, the solution was discarded, and the plates were exposed at RT until dry. The dried plate was sealed and stored at $2-8^{\circ} \mathrm{C}$ until use.

\subsection{3 | Dual-labeled chemiluminescent enzyme immuno-} assay procedure

A schematic illustration of the proposed dual-labeled CLEIA is presented in Figure 2. Before the assay, HRP-labeled anti-TPSA McAb, ALP-labeled anti-FPSA McAb, working solution and calibrators or serum samples, and the antibody coated microwells were equilibrated for $15 \mathrm{~min}$ to RT. First, the calibrators or serum samples, HRP-labeled anti-TPSA McAb working solution and ALP-labeled anti-FPSA McAb working solution with $30 \mu \mathrm{l}$ per well were added into the microplate, then mixed well. Afterwards, incubation was performed in the dark for $30 \mathrm{~min}$ at RT. The solution in the microwells was discarded and the microwells were washed with PBS buffer five times. The microplate was gently tapped against tissue paper to remove all fluid. Chemiluminescence substrates for HRP $(50 \mu \mathrm{L})$ were added into the
Calibration or sample solution $30 \mu \mathrm{L}$

HRP labeled anti-TPSA McAb and ALP labeled anti-PSA McAb working solution $30 \mu \mathrm{L}$ RT, $30 \mathrm{~min}$

Washing with PBS buffer 5 times

Luminol- $\mathrm{H}_{2} \mathrm{O}_{2}$ substrate $50 \mu \mathrm{L}$

RT, 5 min

Chemiluminescence assay for TPSA

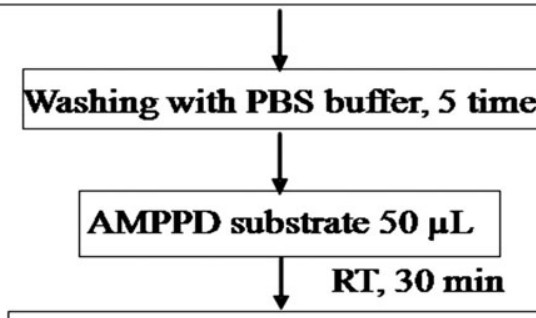

Chemiluminescence assay for FPSA

FIGURE 2 Schematic illustration of the proposed CLEIA procedure

microwells and incubated for $5 \mathrm{~min}$, the photons emitted by the HRP - luminol $-\mathrm{H}_{2} \mathrm{O}_{2}$ system were measured to measure the TPSA concentration. Then, the remaining luminol was removed by washing, AMPPD $(50 \mu \mathrm{L})$ was added to each well and the plate was incubated for 30 min at RT. The photons emitted by the ALP - AMPPD system were used to determine the concentration of FPSA.

\section{6 | Data analysis}

Standards and samples were run in double wells, and the mean chemiluminescence intensity values were taken. Standard curves were obtained by plotting the logarithm value of chemiluminescence $(\mathrm{CL})$ intensity against the logarithm value of analyte concentration and fitted to a linear equation. 


\section{7 | Cross-reactivity studies}

The influence of a set of cross-reactants, including carcino-embryonic antigen (CEA), alpha fetoprotein (AFP), CA199, CA 24-2, CA50 and CA125, was examined at concentrations at least 10 times higher than their normal concentration in human serum. Cross- reactivity (CR) was calculated as follows: $C R=100 \times C_{\text {TPSA }}$ or FPSA $/ C_{\text {cross-reactant }}$, where $\mathrm{C}_{\text {TPSA }}$ or FPSA refers to the value of TPSA or FPSA concentration, which was determined by using the dose-response curve, and the $\mathrm{C}_{\text {cross-reac- }}$ tant refered to as the cross-reactant concentration.

\section{3 | RESULTS AND DISCUSSION}

\subsection{Chemiluminescence kinetics of luminol - HRP and the AMPPD - ALP system}

ALP and HRP have been widely used as labeling enzymes in CLIA. Some chemiluminescent substrates for ALP and HRP have been developed, among them luminol and AMPPD are the most commonly used chemiluminescent substrates for HRP and AMPPD respectively.

The overall kinetics of light emission is shown in Figure 3. For the ALP - AMPPD system: at the beginning of the reaction, $C L$ intensity increased gradually in the time range 0-30 min. After $30 \mathrm{~min}$, light intensity reached a plateau that lasted about $60 \mathrm{~min}$, illustrating that the overall kinetics of the light emission was a two-step process. In

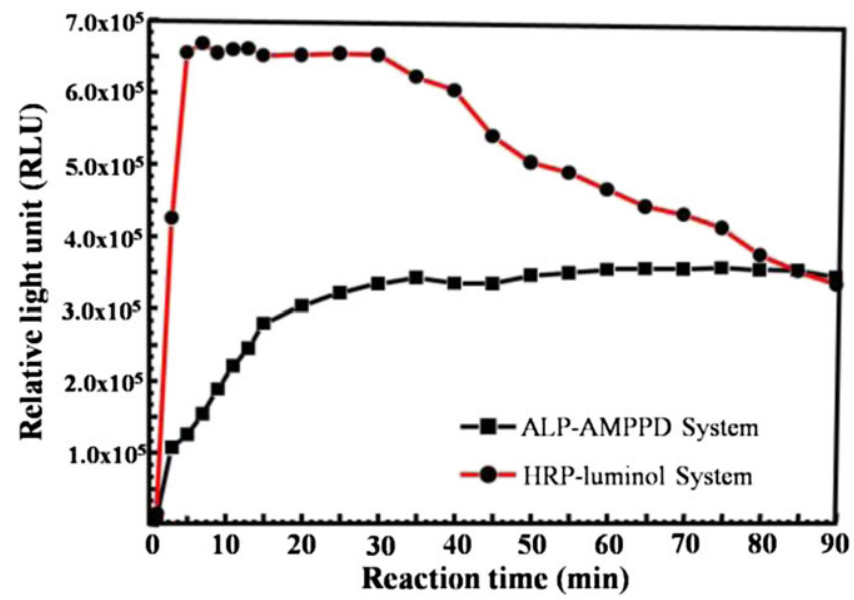

FIGURE 3 Kinetic curves of the ALP - AMPPD and HRP - lumino chemiluminescence systems the first step, when AMPPD was in excess, dephosphorylation was at a constant rate to produce $\mathrm{AMP}^{-} \mathrm{D}$, which is dependent on enzyme concentration. The half-life of the anion was between 2 and 30 min depending on the environment. Due to the slow decomposition of $A M P^{-} D$, the formation of the steady state of chemiluminescene was delayed. In our study, after $30 \mathrm{~min}$, chemiluminescence intensity reached steady state. Therefore, an incubation time of 30 min was selected for detection. ${ }^{[26]}$ For the HRP - luminol system: $\mathrm{CL}$ intensity increased rapidly at the beginning of the reaction in the range of $0-5 \mathrm{~min}$, then $\mathrm{CL}$ intensity reached a plateau in the range of 5-30 min, after $30 \mathrm{~min}, \mathrm{CL}$ intensity decreased gently. So, the incubation time for the chemiluminescence reaction was fixed at $5 \mathrm{~min}$

\section{2 | Optimization of immunoreagents}

The concentration of anti-PSA antibody coating and the amount of enzyme-labeled antibody (including HRP-labeled and ALP-labeled antibodies) could significantly affect the cost, sensitivity and linear range of the chemiluminescence immunoassay, therefore these variables were investigated and optimized in the study.

The anti-PSA antibody was diluted to $2.0,4.0,5.0,6.0$, or $10 \mu \mathrm{g} \mathrm{ml}^{-1}$ with $0.05 \mathrm{M}$ carbonate buffer $\left(0.05 \mathrm{~mol} \mathrm{~L}^{-1}, \mathrm{pH}\right.$ 9.6). The effects of different coating concentrations on the relative luminescence unit (RLU) are presented in Table 1. The RLU of $S_{6}$ and $S_{1}$ increased with increase in anti-PSA coating concentration in the range of $2-5 \mu \mathrm{g} \mathrm{ml}^{-1}$, and then decreased with the further increase in coating concentration. Moreover, the ratios of $\mathrm{RLU}_{\mathrm{S} 1} / \mathrm{RLU}_{\mathrm{SO}}$ and $\mathrm{RLU}_{\mathrm{S} 6} / \mathrm{RLU}_{\mathrm{SO}}$, which indicated the sensitivity and linear range of the assay, also reached maximum when anti-PSA antibody coating concentration was $5.0 \mu \mathrm{g} \mathrm{ml}^{-1}$. Therefore, the anti-PSA antibody coating concentration of $5.0 \mu \mathrm{g} \mathrm{ml}^{-1}$ was selected for further studies.

Both HRP-labeled anti-TPSA antibody and ALP-labeled anti-FPSA antibody were also diluted to $1: 200,1: 500,1: 1000$, or 1:2000 with buffer respectively. The effect of the diluted ratio of enzyme-labeled antibody on the RLU was studied. When the diluted ratio was lower than 1:500, the CL intensity was too high, which meant that the input signal exceeded the acceptable measure range. When the diluted ratio was higher than 1:500, the RLU was lower, and affected the sensitivity of the proposed method. While the diluted ratio was 1:500, RLU was about 300 000, this ratio was used to detect both TPSA and FPSA. In addition, from the experimental data, when the diluted ratio was 1:500, the $S / \mathrm{N}(3.45)$ was lower than that of other diluted ratio, and

TABLE 1 Effect of coating concentration $(n=3)$

\begin{tabular}{|c|c|c|c|c|c|c|}
\hline \multirow[b]{2}{*}{$\begin{array}{l}\text { Coating concentration } \\
\left(\mu \mathrm{g} \mathrm{ml}^{-1}\right)\end{array}$} & \multicolumn{5}{|c|}{ RLU } & \multirow[b]{2}{*}{$\begin{array}{l}\text { Correlation } \\
\text { coefficient }\end{array}$} \\
\hline & $\mathrm{RLU}_{\mathrm{SO}}$ & $\mathrm{RLU}_{\mathrm{S} 1}$ & $\mathrm{RLU}_{\mathrm{S6}}$ & $\mathrm{RLU}_{\mathrm{S} 1 / \mathrm{SO}}$ & $\mathrm{RLU}_{\mathrm{S6} / \mathrm{SO}}$ & \\
\hline 2 & 317 & 15567 & 414357 & 49 & 1307 & 0.9290 \\
\hline 4 & 309 & 45697 & 698536 & 148 & 2260 & 0.9966 \\
\hline 5 & 323 & 53516 & 773537 & 165 & 2395 & 0.9989 \\
\hline 6 & 386 & 44893 & 748116 & 116 & 1938 & 0.9973 \\
\hline 10 & 506 & 51183 & 685771 & 133 & 1355 & - \\
\hline
\end{tabular}


the correlation coefficient was more than 0.9980 . Therefore, a diluted ratio of 1:500 was selected in our experiment.

Usually, the volume of reaction mixture should be less than the volume of coating antibody. In the sandwich immunoassay reaction, the formation of the $\mathrm{Ab}-\mathrm{Ag}-\mathrm{Ab}$ immunocomplex demanded that the amount of both the coating antibody and the enzyme-labeled antibody should be no less than the amount of antigen. So the chessboard method was used to optimize the immunoassay reaction, and $30 \mu \mathrm{L}$ of ALP-labeled anti-TPSA McAb, $30 \mu \mathrm{L}$ of HRP-labeled anti-FPSA McAb, and $30 \mu \mathrm{L}$ of calibrators or serum samples were chosen for the proposed method in this study.

\section{3 | Effect of standard matrix}

It was well known that the standard matrix had a significant effect on the standard stability in clinical analysis, especially for proteins with high biological activities. ${ }^{[27]}$ Therefore, four different types of sera ( $100 \%$ calf serum, $50 \%$ calf serum, human serum and equine serum), which were used as matrix for calibrator preparation, were analyzed to investigate the performance differences. The ratio of RLU between $\mathrm{S} 1$ and SO $\left(\mathrm{RLU}_{\mathrm{S} 1} / \mathrm{RLU}_{\mathrm{SO}}\right)$ and the coefficient of variation (CV), which

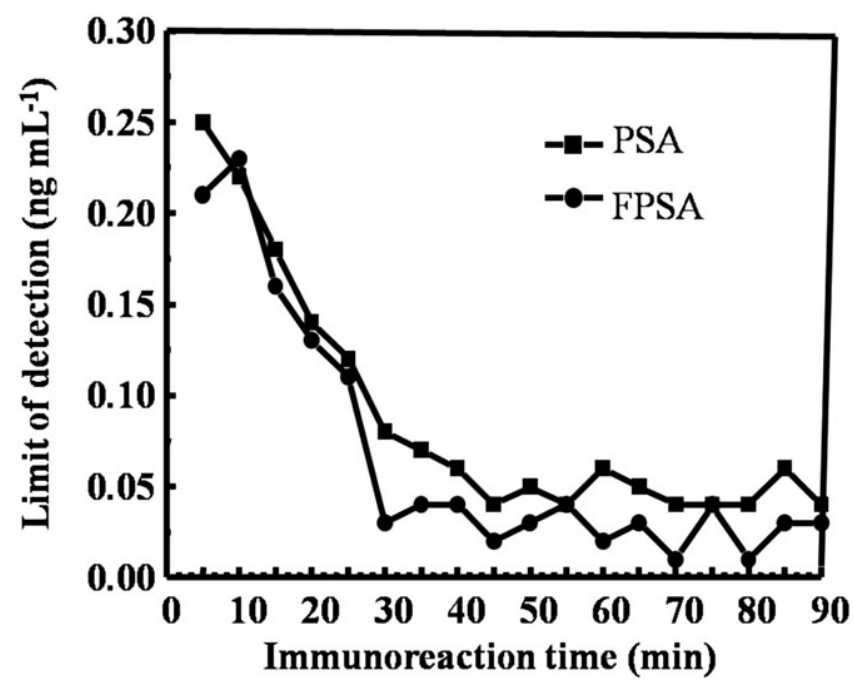

FIGURE 4 Effect of immunoreaction time on the assay sensitivity was an indicator for the sensitivity and the precision of the assay, was calculated using three replicates per day for 3 days. The results showed that $50 \%$ calf serum sample had the lowest $C V$ and the highest $\mathrm{RLU}_{\mathrm{S} 1} / \mathrm{RLU}_{\mathrm{SO}}$ value (data not shown). Therefore, $50 \%$ calf serum was chosen as the standard matrix for the PSA calibrator preparation.

\subsection{Effect of immunoreaction time}

Immunoreaction time was one of the key factors that could determine the sensitivity of the immunoassay. For this reason, different immunoreaction times from $5 \mathrm{~min}$ to $90 \mathrm{~min}$ were taken to assess the effect on the assay. As shown in Figure 4, the limit of detection (LOD), defined as the minimum dose distinguishable from zero, or the minimum detected concentration (mean - 3 SD of zero standard, eight replicates), decreased significantly for both TPSA and FPSA when the assay time increased from $5 \mathrm{~min}$ to $30 \mathrm{~min}$. After $30 \mathrm{~min}$, the LOD became stable. The results indicated that under these condition the reaction

TABLE 2 Precision profiles of TPSA and FPSA immunoassay

\begin{tabular}{lrrrrr} 
& \multicolumn{2}{c}{ Intra-assay $^{\mathbf{a}}$} & & \multicolumn{2}{c}{ Inter-assay $^{\mathbf{b}}$} \\
\cline { 2 - 3 } \cline { 5 - 6 } & Mean & CV (\%) & & Mean & CV (\%) \\
\hline TPSA (ng ml & -1) & 5.63 & 6.26 & 5.51 & 8.21 \\
& 28.05 & 6.95 & 27.07 & 7.42 \\
FPSA (ng ml ${ }^{-1}$ ) & 5.43 & 8.38 & 5.31 & 9.01 \\
& 26.64 & 2.93 & 26.35 & 4.08
\end{tabular}

Ten duplicate assay for each sample.

'Three separate assay runs (10 duplicate for each sample) in 3 days.

TABLE 3 Cross-reactivity analysis with other tumor markers

\begin{tabular}{|c|c|c|c|}
\hline \multirow[b]{2}{*}{$\begin{array}{l}\text { Tumor } \\
\text { markers }\end{array}$} & \multirow[b]{2}{*}{$\begin{array}{c}\text { Labeled } \\
\text { concentration }\end{array}$} & \multicolumn{2}{|c|}{ Determined concentration $\left(\mathrm{ng} \mathrm{ml}^{-1}\right)$} \\
\hline & & TPSA & FPSA \\
\hline CEA & $162 \mathrm{ng} \mathrm{ml}^{-1}$ & 0.12 & 0.06 \\
\hline AFP & $1600 \mathrm{ng} \mathrm{ml}^{-1}$ & 0.04 & 0 \\
\hline CA199 & $600 \mathrm{ng} \mathrm{ml}^{-1}$ & 0.01 & 0 \\
\hline Ca $24-2$ & $600 \mathrm{U} \mathrm{ml}^{-1}$ & 0.01 & 0 \\
\hline CA50 & $140 \mathrm{U} \mathrm{ml}^{-1}$ & 0 & 0 \\
\hline CA125 & $2500 \mathrm{U} \mathrm{ml}^{-1}$ & 0.02 & 0.01 \\
\hline
\end{tabular}
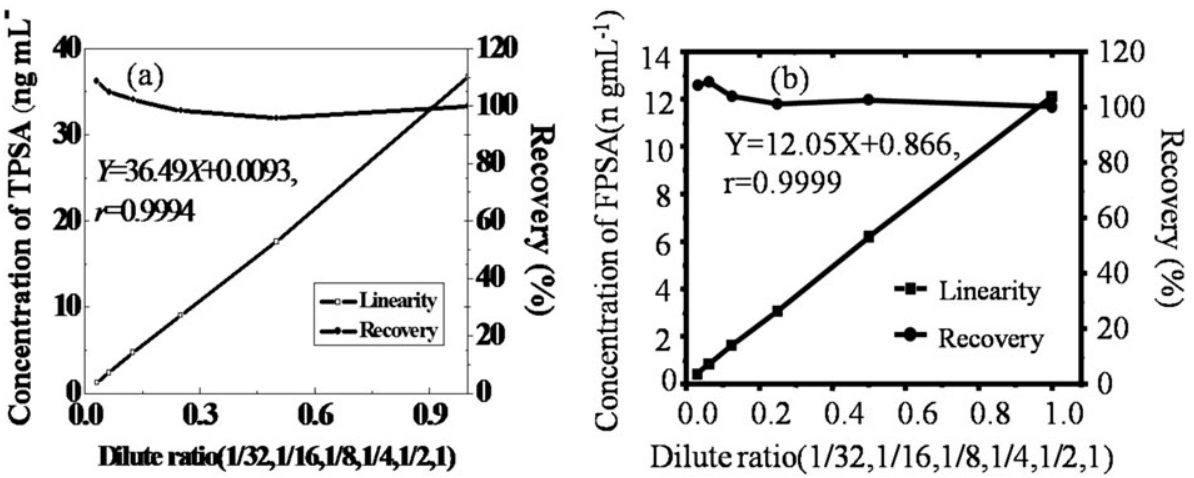

FIGURE 5 (a) the linearity and recovery of the TPSA immunoassay, data points presented the dilute ratio of $1 / 32,1 / 16,1 / 8,1 / 4,1 / 2$ and 1 from left to right, respectively. (b) the linearity and recovery of the FPSA immunoassay, data points presented the dilute ratio of $1 / 32,1 / 16,1 / 8,1 / 4,1 /$ 2 and 1 from left to right, respectively 

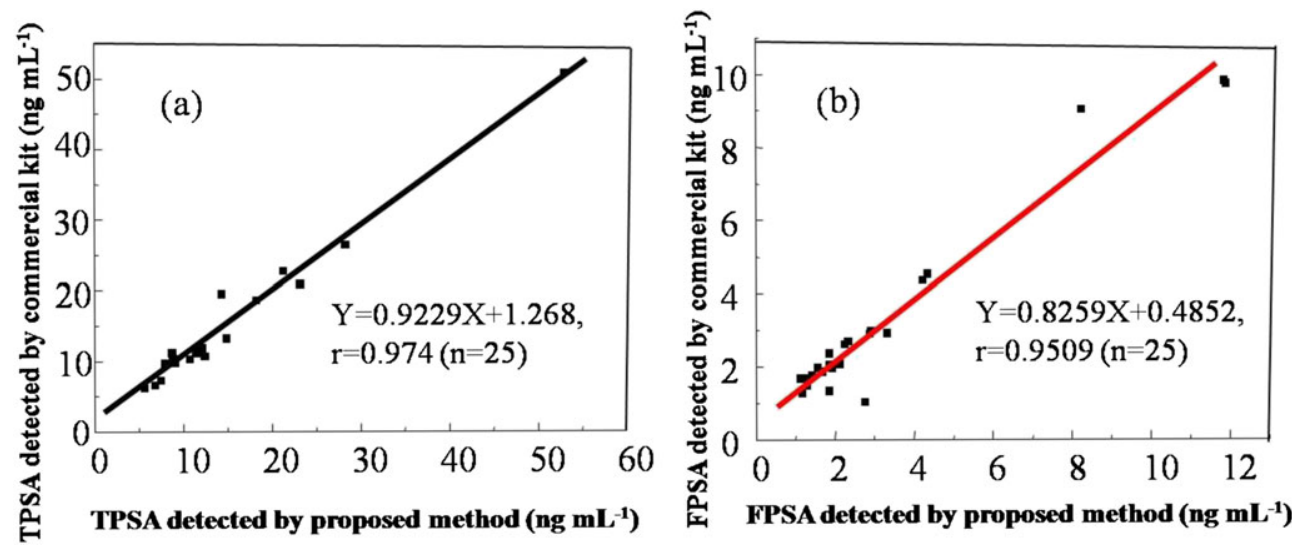

FIGURE 6 (a) correlation between the data obtained from the proposed dual-labeled method and commercial kit for TPSA. (b) correlation between the data obtained from the proposed dual-labeled method and commercial kit for FPSA

between antibody and antigen would take 30 min to reach the equilibrium. Therefore, a 30 min immunoreaction time was selected as the optimum time for the assay.

\section{5 | Linear standard curve, sensitivity and recoveries}

One pooled serum was used as the standard. Under optimal conditions, linearity was assessed by diluting the human serum samples with a TPSA concentration of $36.7 \mathrm{ng} \mathrm{ml}^{-1}$ and a FPSA concentration of $12.1 \mathrm{ng} \mathrm{ml}^{-1}$, respectively. The sera were diluted by two-, four-, eight-, or 16 -fold with the standard matrix. The sensitivity was measured to be 0.03 and $0.05 \mathrm{ng} \mathrm{ml}^{-1}$ for FPSA and TPSA, respectively. The expected value of the diluted sample was calculated from the concentration measured in the undiluted sample. Analytical recoveries were tested by combining intermediate concentrations of standard with low concentration human serum. As shown in Figure 5(a, b), the linear correlations between dilute ratio $(X)$ and measured $(Y)$ values were as following: for TPSA, $Y=36.49 X+0.0093(r=0.9994)$, and for FPSA, $Y=12.03 X+0.0866(r=0.9999)$. Analytical recoveries between measured and expected values were from $95.7 \%$ to $109.0 \%$, and $90 \%$ to $110 \%$, for TPSA and FPSA, respectively.

\subsection{Evaluation of the proposed method}

Real serum samples for TPSA and FPSA were used in our experiments to evaluate the performance of the proposed method. All assays were performed at RT. Unless specific stated, the presented experimental data were the mean of three times analyzes.

Precision was an important standard for a clinical immunoassay and indicated the reliability as well as the stability of the assay method. In this experiment, two different sera with quality controls were analyzed, 10 replicates each, to evaluate the intra-assay (CV) and the inter-assay CV in 3 days. As shown in Table 2, the intra-assay CV for FPSA and TPSA were $2.93-8.38 \%$, and $6.26-6.95 \%$, respectively, meanwhile the inter-assay CV for FPSA and TPSA were 4.08-9.01\% and $7.42-8.21 \%$, respectively.

The parallelism and recovery were assessed by diluting two human sera with a TPSA concentration of $36.7 \mathrm{ng} \mathrm{ml}^{-1}$ and a FPSA concentration of $12.1 \mathrm{ng} \mathrm{ml}^{-1}$ as described above, which indicated that the proposed method was reliable and suitable for the real clinical assay.

\section{7 | Cross-reactivity}

The cross-reactivity of the proposed dual-labeled CLEIA was evaluated using some common tumor markers in serum such as CEA, AFP, CA199, CA 24-2, CA50, and CA125 with at least 10 times higher concentrations than their normal concentrations in the human body. As shown in Table 3, the results indicated that there was no cross-reaction between TPSA or FPSA and other tumor markers.

\subsection{Determination of TPSA and FPSA in serum sample}

The concentrations of TPSA and FPSA in 25 clinical patients' sera were measured with the proposed method and the results were compared with that obtained by using commercial chemiluminescent kits, which measured TPSA and FPSA separately. As shown in Figure 6, the linear correlations between the results obtained from the proposed method $(x)$ and from CL kits (y) were: for TPSA, $y=0.9229 x+1.268$ $(r=0.987)$; and for FPSA, $y=0.8259 x+0.4852(r=0.975)$

\section{4 | CONCLUSION}

A dual-labeled CLEIA was successfully established for simultaneous measurement of TPSA and FPSA. Horseradish peroxidase (HRP)labeled anti-TPSA monoclonal antibody (McAb) and ALP-labeled antiFPSA McAb was used as the detection antibody, anti-PSA McAb (Mab1) was immobilized on a microplate as the solid phase, based on a sandwich immunoassay model. The amount of FPSA and TPSA could be determined simultaneously by the readout of chemiluminescence $(\mathrm{CL})$ signal. The effects of several physico-chemical parameters and the cross-reactivities of six common tumor markers in serum were studied. Two commercial chemiluminescent kits for the measurement of TPSA and FPSA respectively were used as the control methods. In the optimum conditions, the intra- and inter-assay coefficients of variation were both below $9.01 \%$. The recoveries were in the range 
of 95.7 to $109 \%$. Six common tumor markers showed no cross-reactivity with the present method. The assay correlated well with commercial kit for the determination of TPSA and FPSA in clinical serum samples. In conclusion, this proposed method could be used to simultaneously measure the concentrations of FPSA and TPSA in serum samples with dual-enzyme-labeled and high sensitivity chemiluminescence, which was a great improvement to traditional methods, and also could greatly facilitate the diagnosis for PCa in the clinical practice.

\section{ACKNOWLEDGEMENTS}

The authors gratefully acknowledge financial support from the National Key Research and Development Program of China (2016YFA0203102), the Chinese Academy of Sciences (XDB14040100), and the National Natural Science Foundation of China (Nos 21677152, 21177138).

\section{REFERENCES}

[1] M. V. Dwek, A. Jenks, A. J. C. Leathem, Clin. Chim. Acta 2010, 411, 1935.

[2] L. Zhu, J. Leinonen, W. M. Zhang, P. Finne, U. H. Stenman, Clin.Chem. 2003, 49, 97.

[3] D. Ulmert, C. Becker, J. Nilsson, T. Piironen, T. Bjork, J. Hugosson, G. Berglund, H. Lilia, Clin. Chem. 2006, 52, 235.

[4] K. Matsumoto, N. Konishi, T. Samori, E. Kimura, M. Doi, S. Kato, Y. Yuki, J. Immunol. Methods 2000, 234, 99.

[5] A. M. Zhou, P. C. Tewari, B. I. Bluestein, G. W. Caidwell, F. L. Larsen, Clin. Chem. 1993, 39, 2483.

[6] C. D. Cheli, M. Marcus, J. Levine, Z. Zhou, P. H. Anderson, D. D. Bankson, J. Bock, S. Bodin, C. Eisen, M. Senior, M. K. Schwartz, K. K. Yeung, W. J. Allard, Clin. Chem. 1998, 44, 1551.

[7] K. Mitrunen, K. Pettersson, T. Piironen, T. Bjork, H. LiLja, T. Lovgren, Clin. Chem. 1995, 41, 1115.

[8] D. W. Chan, D. J. Bruzek, J. E. Oesterllng, R. C. Rock, P. C. Walsh, Clin. Chem. 1987, 33, 1916.

[9] T. Kotto, T. Liljenback, M. T. Peltola, L. Kokko, T. Soukka, Anal. Chem. 2008, 80, 9763.

[10] B. Y. Wu, X. P. Yan, Chem. Comm. 2015, 51, 3903.
[11] H. H. Jeong, N. Erdene, J. H. Park, D. H. Jeong, H. Y. Lee, S. K. Lee, Biosen. Bioelectron. 2013, 39, 346.

[12] R. K. Gao, Z. Y. Cheng, A. J. Demello, J. Choo, Lab on Chip 2016, 16, 1022.

[13] Z. Feng, J. Zhou, D. Chen, S. Wang, X. Wang, S. Xie, Chin. J. Lumin. 2015, 36, 1064.

[14] G. Shi, B. J. Tang, X. Wang, L. X. Zhao, J.-M. Lin, Chin. J. Anal. Chem. 2007, 35, 1541.

[15] R. P. Liu, C. Wang, Q. Jiang, W. Jiang, W. Zhang, Z. Yue, G. H. Liu, Anal. Chim. Acta 2013, 801, 91.

[16] S. J. Xu, Y. Liu, T. H. Wang, J. H. Li, Anal. Chem. 2011, 83, 3817.

[17] F. Zhang, L. Mao, M. Q. Zhu, Microchem. Acta 2014, 181, 1285.

[18] F. Oberpenning, C. Weining, B. Brandt, G. D. Angelis, A. Heinecke, M. Hamm, P. Stieber, L. Hertle, H. P. Schmid, A. Semionow, Eur. Urol. 2002, 42, 577.

[19] C. Stephan, M. Klaas, C. Muller, D. Schnorr, S. Loening, K. Jung, Clin. Chem. 2006, 52, 59.

[20] R. Junker, B. Brandt, C. Zechel, G. Assmann, Clin. Chem. 1997, 43, 1588.

[21] C. Xie, G.-M. Wang, J. Clin. Lab. Anal. 2011, 25, 37.

[22] Z. Li, Q. Zhang, L. Zhao, Z. Li, G. Hu, J.-M. Lin, S. Wang, Sci. China Chem. Sci. China, Chem. 2010, 53, 812.

[23] Q. Xiao, H. Li, J.-M. Lin, Clin. Chim.Acta 2010, 411, 1151.

[24] G. Zheng, H. Chen, X. Ying, G. Hu, J.-M. Lin, Sci. Sinica Chim. 2011, 41, 1177.

[25] Q.-Y. Zhang, H. Li, H. Chen, Z. Lin, J.-M. Lin, J. Pharm. Anal. 2012, 2, 130.

[26] L. Zhao, J.-M. Lin, J. Biotechnol. 2005, 118, 177.

[27] X. Wang, Q.-Y. Zhang, Z. Li, X.-T. Ying, J.-M. Lin, Clin. Chim. Acta 2008 $393,90$.

How to cite this article: Zhao L, Wang D, Shi G, Lin L. Duallabeled chemiluminescence enzyme immunoassay for simultaneous measurement of total prostate specific antigen (TPSA) and free prostate specific antigen (FPSA). Luminescence. 2017;32:1547-1553. https://doi.org/10.1002/bio.3358 